\title{
OS CONHECIMENTOS DO PROFESSOR PARA ENSINAR MATEMÁTICA NO MANUAL DIDÁTICO BRASILEIRO DO TERCEIRO ANO DO ENSINO FUNDAMENTAL
}

\author{
THE TEACHER'S KNOWLEDGE FOR TEACHING MATHEMATICS AT \\ BRAZILIAN DIDACTIC MANUAL FOR THE THIRD YEAR OF ELEMENTARY \\ EDUCATION
}

EL CONOCIMIENTO DEL PROFESOR PARA LA ENSEÑANZA DE MATEMÁTICAS EN EL MANUAL DIDÁCTICO BRASILEÑO PARA EL TERCER AÑO DE EDUCACIÓN PRIMARIA

\author{
Camila Fernanda Pereira da Luz* (D) 9 \\ Edvonete Souza de Alencar** (D) 9
}

\begin{abstract}
RESUMO
O presente trabalho faz parte de uma investigação do Programa Institucional de Bolsas de Iniciação Científica (PIBIC), uma análise bibliográfica de caráter qualitativa, a qual o objetivo é evidenciar os subdomínios que aparecem no manual do professor que ensina a matemática no terceiro ano do ensino fundamental. O Mathematics Teaching Specialisedge - (MTSK) é um modelo utilizado por nós como uma ferramenta afim de refletir, investigar, mas nunca com o intuito de medir de maneira classificatória. Este estudo revela nas orientações específicas de cada unidade temática, que os subdomínios pertencentes ao Mathematical knowledge - (MK), aparecem 21 vezes, enquanto os subdomínios referentes ao Pedagogical content knowledge - (PCK) aparecem apenas 19 vezes. Isso nos revela que o conhecimento matemático, se sobressai nas orientações, mas que o conhecimento pedagógico complementa no planejamento das ações do professor e também em sua prática.
\end{abstract}

Palavras-chave: Ensino Especializado. Manual Didático. Educação Matemática.

\begin{abstract}
The present work is part of an investigation of the Institutional Program for Scientific Initiation Scholarships (PIBIC), a qualitative bibliographic analysis, which aims to highlight the subdomains that appear in the teacher's manual that teaches mathematics in the third year of education. fundamental. The Mathematics Teaching Specializedge - (MTSK) is a model used by us as a tool to reflect, investigate, but never with the aim of measuring in a classificatory way. This study reveals in the specific guidelines of each thematic unit, that the subdomains pertaining to Mathematical knowledge - (MK), appear 21 times, while the subdomains referring to Pedagogical content knowledge - (PCK) appear only 19 times. This reveals that mathematical knowledge stands out in the guidelines, but that pedagogical knowledge complements the planning of teacher actions and also in their practice.
\end{abstract}

Keywords: Specialized Teaching. Didactic Manual. Mathematics Education.

* Graduação em Pedagogia-Licenciatura pela Universidade Federal da Grande Dourado (UFGD). Trabalho
Independente. E-mail: camila.ademir21 @ gmail.com
** Doutora em Educação Matemática pela Pontifícia Universidade Católica de São Paulo (PUC- SP). Professora
na Universidade Federal da Grande Dourados (UFGD), Dourados, Mato Grosso do Sul, Brasil. Endereço
profissional: Rua João Rosa Góes, 1761 - Caixa Postal 322 - Bairro: Vila Progresso - CEP: Dourados, Mato Grosso
do Sul, Brasil CEP: 79825-070. E-mail: edvonete.s.alencar @ hotmail.com. Universidade Federal de Mato Grosso, Cuiabá, Mato Grosso, Brasil. Revista REAMEC - Rede Amazônica de Educação em Ciências e Matemática, v. 10, n. 1, e22009, janeiro-abril, 2022. 


\section{RESUMEN}

El presente trabajo forma parte de una investigación del Programa Institucional de Becas de Iniciación Científica (PIBIC), un análisis bibliográfico cualitativo, que tiene como objetivo resaltar los subdominios que aparecen en el manual del docente que enseña matemáticas en el tercer año de educación fundamental. La Especialización en Enseñanza de las Matemáticas - (MTSK) es un modelo que utilizamos como herramienta para reflexionar, investigar, pero nunca con el objetivo de medir de manera clasificatoria. Este estudio revela en los lineamientos específicos de cada unidad temática, que los subdominios pertenecientes al Conocimiento Matemático - (MK), aparecen 21 veces, mientras que los subdominios referentes al Conocimiento del Contenido Pedagógico - (PCK) aparecen solo 19 veces. Esto revela que el conocimiento matemático se destaca en las directrices, pero que el conocimiento pedagógico complementa la planificación de las acciones docentes y también en su práctica.

Palabras clave: Educación especializada. Manual didáctico. Educación matemática.

\section{INTRODUÇÃO}

O trabalho iniciado ano passado, a bolsa de pesquisa, com duração de um ano, fez a análise do livro da coleção ÁPIS correspondente ao primeiro ano do ensino fundamental; agora damos continuidade ao trabalho analisando o manual didático da coleção equivalente ao terceiro Ano do ensino fundamental. O projeto de investigação de manuais didáticos faz parte de uma rede Iberomericana de pesquisa, que analisa cada exemplar de acordo com o ano escolar correspondente, anos iniciais do ensino fundamental. Escolhemos o material de pesquisa de acordo com levantamento de dados do Plano Nacional de do livro Didático - PNLD. Objetivamos evidenciar quais os subdomínios do conhecimento especializado são mobilizados pelo professor que ensina a matemática no terceiro ano.

$\mathrm{O}$ nosso referencial teórico continua sendo o modelo O Mathematics Teaching Specialisedge (MTSK), que traz o conhecimento especializado do professor que ensina matemática, de maneira detalhada. O MTSK se preocupou em aprimorar os conhecimentos sobre o professor já existentes, Moriel Junior e Carrillo (2014) mencionam que inicialmente o MTSK foi investigado pelos autores Ball e Shulman o modelo descreve o conhecimento que é específico dos professores que ensinam a matemática, para isso ele compreende esse saber em duas grandes áreas, o Conhecimento matemático (MK) e o Conhecimento pedagógico do conteúdo (PCK). Estes dois domínios se dividem em três subdomínios que são mobilizados pelos docentes em seu trabalho, ao centro temos as crenças que colaboram as ações dos professores e incorporam significado para elas.

Os seis subdomínios descrevem como entender o conhecimento específico de um professor de Matemática e servem como "categorias" de análise em investigações. Por isso, o MTSK também pode ser considerado uma ferramenta metodológica para 
exploração analítica deste conhecimento. (MORIEL JUNIOR e CARRILLO, 2014, p. 466)

Os subdomínios pertencentes ao conhecimento matemático (MK) estabelecem, que o professor precisa ter um bom conhecimento das regras matemáticas e sua criação, permitindo assim um ensino de maneira conectada para validar as suas hipóteses e de seus alunos. $\mathrm{O}$ conhecimento de tópicos matemáticos (KOT), se refere aos conteúdos que compõem o currículo, "reunindo conhecimento de procedimentos, definições e propriedades, representações e modelos, bem como contextos, problemas e significados" (CARRILLO, 2018, p. 08), o conhecimento da estrutura da matemática (KSM) dez respeito as conexões entre as unidades, por meio da simplificação (quando volta a trabalhar conteúdos anteriores), ou por meio da complexidade (quando menciona conteúdos que serão trabalhados posteriormente), e o conhecimento da prática matemática (KPM) enfatiza o papel do professor em sala de aula "permitindo que eles gerenciem o raciocínio matemático colocados em jogo pelos alunos, aceitando, refutando ou refinando-o conforme necessário” (CARRILLO, 2018, p. 10).

Os subdomínios pertencentes ao conhecimento pedagógico do conteúdo (PCK) permitem o professor ser crítico e reflexivo, além de dar ênfase a literatura e a pesquisa como fonte do conhecimento para ensinar a matemática. O conhecimento de características da aprendizagem de matemática (KFLM), tem o foco no conteúdo na experiencia adquirida ao longo do tempo, "incorpora conhecimento dos estilos de aprendizagem e diferentes maneiras de perceber as características inerentes a determinado conteúdo" (CARRILLO, 201, p. 12). Em contrapartida o conhecimento do ensino de matemática (KMT), está ligado ao conteúdo com exclusão dos aspectos pedagógicos, “em termos de conteúdo específico, envolve a conscientização do potencial de atividades, estratégias e técnicas para ensinar conteúdo matemático específico" (CARRILLO, 2018, p. 12), e por último o conhecimento das normas da aprendizagem de atemática (KMLS) faz atribuições para aprender e construir a matemática em qualquer estágio, "este subdomínio inclui o conhecimento do professor sobre tudo o que aluno deve ou é capaz de alcançar em um nível específico”(CARRILLO, 2018, p. 13). 


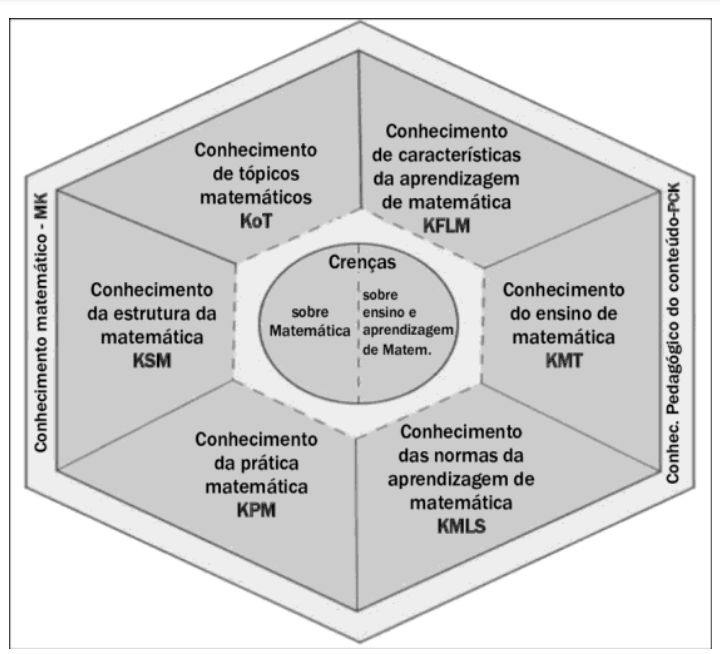

Figura 01: Modelo MTSK

Fonte: MORIEL JUNIOR, Jeferson G. (2014)

A imagem nos mostra a representação gráfica do modelo, as crenças estão localizadas ao centro e abrangem todos os subdomínios, pois fazem parte de consciente dos professores, e são introduzidos ao longo de toda a sua trajetória pessoal e profissional. Observamos os subdomínios ao redor das crenças, com a tradução em língua portuguesa, mas as siglas continuam sendo das palavras na língua inglesa, assim podemos observar as referências de acordo, com o texto e o quadro original do modelo construído pelo grupo de pesquisa, SIDM da Universidade de Huelva (Espanha). Logo a questão norteadora da pesquisa é: quais subdomínios do modelo MTSK, encontraremos no manual didático do professor, que ensina matemática no terceiro ano do ensino fundamental.

\section{METODOLOGIA}

A pesquisa faz parte da investigação de iniciação científica, buscamos encontrar os subdomínios do MTSK, no manual didático do terceiro ano do ensino fundamental, destacandoos e organizamos tabelas para demonstração dos resultados. Escolhemos uma abordagem qualitativa dos manuais, pois (Ludke, 1986) nos orienta que:

Em primeiro lugar destacam o fato de que os documentos constituem uma fonte estável e rica. Persistindo ao longo do tempo, os documentos podem ser consultados várias vezes e inclusive servir de base a diferentes estudos, o que dá mais estabilidade aos resultados obtidos. (LUDKE, 1986, p. 39)

Um mesmo manual ode ser utilizado em diferentes contextos com diferentes abordagens, o MTSK nos auxilia na prática em sala de aula, mostrando quais os subdomínios utilizados em determinada ação, tornando o trabalho do professor mais reflexivo. Com isso podemos localizar e desenvolver outros tópicos numa mesma ação. 
Desse modo organizamos o seguinte quadro com as etapas de nossa investigação:

- Levantamento bibliográfico

- Leitura

- Seleção

- Categorização

- Análise

- Escrita

Na primeira fase o levantamento bibliográfico feito a partir de pesquisas on-line no site do PNLD, para encontrar qual manual didático foi mais distribuído na rede pública de ensino. Juntamente com a busca de artigos sobre o conhecimento especializado do professor que ensina matemática. A segunda fase de leitura foi feita individualmente, por cada uma das pesquisadoras.

Depois de organizar os dados, num processo de inúmeras leituras e releituras, o pesquisador pode voltar a examiná-los para tentar detectar temas e temáticas mais freqüentes. Esse procedimento, essencialmente indutivo, vai culminar na construção de categorias ou tipologias. (LUDKE, 1986, p. 42)

Assim sendo, a fase de seleção foi feita por meio de leitura de cada unidade temática encontrada no livro, retirando os trechos de comando sobre as atividades e o intuito de cada uma delas, que estavam direcionadas para o professor e voltadas a sua prática. A categorização foi a classificação de cada trecho juntamente com a análise foram então construídos os quadros especificando qual subdomínio fora encontrado. A escrita foi feita ao longo de todo o processo, com as orientações da professora Dr. Edvonete Alencar simultaneamente com as observações do grupo de pesquisa “TeiaMat”, da Universidade Federal da Grande Dourados-UFGD.

\section{APRESETAÇÃO DOS DADOS}

O manual do professor tem trezentas páginas neste livro, quarenta e oito são de orientações e explicações gerais sobre como foi pensado e escrito manual didático, cujo autores são Luiz Roberto Dante, publicado pela editora ática. No manual são explicados logo de início a legislação vigente e as competências da BNCC que são encontradas em cada unidade a ser estudada durante o ano. Depois começa uma réplica do livro com as anotações e as atividades pertencentes aos alunos, porém com as respostas nas atividades e as observações feitas pensando exatamente no professor que irá utilizar o livro como recurso. 
Assim, como o Livro do primeiro volume analisado anteriormente, este manual é igualmente dividido em oito unidades temáticas, cada unidade trata de uma parte específica do conhecimento matemático, dentro de cada unidade temos as conexões de simplificação e/ou complexidade. A coleção é composta por cinco grandes livros que contém páginas de orientação e recomendações, além do material digital que está disponível apenas para os professores. $\mathrm{O}$ material digital é complementar ao material impresso, são orientações quadros, sugestões de atividades, propostas de projetos e avaliação, fichas de acompanhamento entre outros. com o intuito de auxiliar a organização e o planejamento dos professores.

A parte geral, passa informações e aponta os objetivos da educação matemática na perspectiva dos seus organizadores, esclarece cada uma das unidades temáticas, revela as atribuições que são exigidas na BNCC e traz informações sobre como chegar na decisão de sua criação e escrita. A coleção se preocupa com o ensino em espiral, ou seja, ele retorna nos conceitos fundamentais dos conteúdos, tornando assim o ensino mais significativo, em uma sequência mais interativa com os outros conteúdos esperados. Separamos em cada unidade cinco trechos de ações e/ou orientações principais, que evidenciamos de maneira clara os domínios pertencentes ao MTSK, organizando-os em quadros, destacamos também os objetivos a serem atingidos em cada unidade temática.

O didático apresenta seções que se repetem em cada unidade, no manual são incluídos comentários, exemplificando essas seções, sendo composto por dicas relevantes, referentes a cada atividade, e fazendo observações sobre livros, músicas, sites para pesquisas extracurriculares, e mencionando a conexões entre as unidades do material sequencial, e também dos exemplares do ano anterior. Essas seções estão destacadas com os nomes de "vamos ver de novo" e "o que estudamos". O próprio título nos sugere uma regressão ao que tínhamos visto antes, esse movimento pode auxiliar-nos a perceber o que o aluno já sabia antes de ser apresentado, e depois das aulas, mostrando assim seu progresso, evolução ou até mesmo alguma dificuldade, dando ao professor a oportunidade de aprimorar mais a demonstração de conteúdo por meio da autorreflexão.

\section{RESULTADOS OBTIDOS}

A coleção preocupa-se com a demonstração da organização estrutural de todos os conteúdos, apresentando os assuntos que serão trabalhados antes mesmo de iniciar as- unidades. Inicia-se o trabalho apresentando para o aluno as propriedades matemáticas que ele já está 
habituado a ver, utilizar e solucionar em sua rotina, de maneira natural, desde que estejam seguindo o currículo nacional, na página onze por exemplo observamos uma ficha disponibilizada para cada aluno preencher de maneira particular, mas trazendo nessa ficha elementos que serão apresentados no decorrer do livro desde a primeira até a oitava unidade.

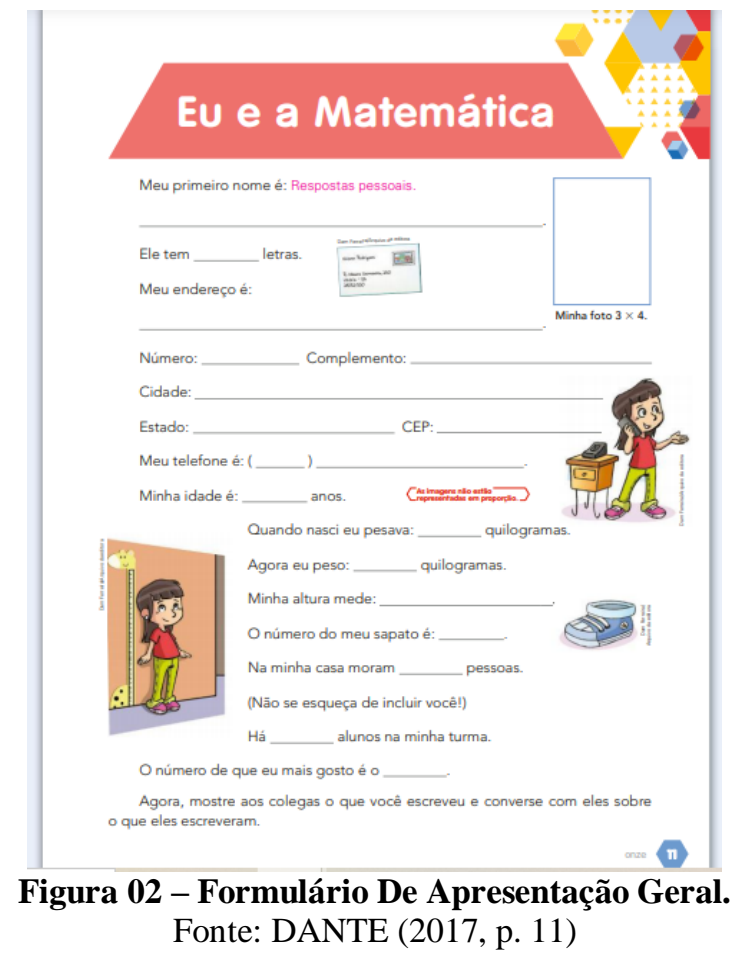

\section{Unidades 1 e 2: Números até 1000 e Geometria}

Nessas duas unidades é trabalhado de forma muito explicativa e lúdica, inicia-se na primeira unidade, a história dos números trazendo para o cotidiano o sistema de numeração decimal, assim abrindo a contagem e demonstração dos números até o 999. São ilustradas histórias sobre como a ideia de como o número surgiu e qual a necessidade de contar e como as representações simbólicas se deram ao longo dos anos. todas as observações são introduzidas como questionamentos fazendo com que os alunos agucem a vontade de pesquisar e aprofundar para a melhor compreensão do sistema de numeração. Fazendo jus aos primeiros objetivos esperados.

Objetivos desta Unidade • mostrar, como e onde os números são usados. • Compreender os números até 1000 . Ler, escrever e ordenar números até 1000 . • Compreender o sistema de numeração decimal (unidades, dezenas e centenas). • Identificar sucessor, antecessor, números pares e números ímpares. • Ler e escrever números ordinais. (DANTE, 2017, p. 12) 
Como destacamos, temos uma demonstração de como se deu o sistema de numeração decimal, para depois combinar números que resultem em centenas, dezenas e unidades que representem, decomponham os algoritmos, afim de trabalhar as centenas do enunciado da unidade, trabalhando os números pares e impares, trazendo a ordem e o sucessor e o antecessor dos números e a nomenclatura dos números ordinais. Nessas. Já nos objetivos da segunda unidade as demonstrações podem ser mais físicas, utilizando de técnicas e objetos do dia-a-dia para fixar os conceitos do conteúdo.

\footnotetext{
Objetivos desta Unidade • Reconhecer os sólidos geométricos cubo, paralelepípedo, prisma, pirâmide, esfera, cilindro e cone. $•$ Identificar sólidos geométricos que podem rolar e que não rolam. - Reconhecer as regiões planas retangulares, quadradas, triangulares e circulares e seus contornos (retângulo, quadrado, triângulo e circunferência). • Localizar objetos no plano e fazer deslocamentos (DANTE, 2017, p. 34)
}

Depois dos sólidos geométricos o livro apresenta prismas e pirâmides para então adentrar em sólidos que não rolam, em regiões planas apresentamos o Tangram, com a perspectiva de fazer ligações Inter conceituais da geometria geral no livro.

Assim organizamos as principais orientações das duas unidades no seguinte quadro, evidenciando as competências encontradas pertencentes ao PCK na primeira unidade e ao MK na segunda unidade, o conhecimento pedagógico do conteúdo reflete a prática em sala de aula, “o foco específico do PCK está relacionado à própria matemática. Mais do que ser sobre a interseção entre conhecimentos matemáticos e pedagógicos gerais, é um tipo específico de conhecimento de pedagogia que deriva principalmente da matemática." (CARRILLO, 2018, p.11). Logo, ele complementa as competências que utilizamos do conhecimento matemático. Na segunda unidade esse cenário se inverte e encontramos predominantemente o MK, que nos demonstra o conhecimento necessário ao professor sobre as conexões matemáticas observadas em rede, que compreendem as técnicas e a fenomenologia que utilizamos ao apresentar os conteúdos nesta etapa de ensino.

\begin{tabular}{|c|c|}
\hline TRECHO & $\begin{array}{l}\text { SUBDOMINIO } \\
\text { MTSK }\end{array}$ \\
\hline \multicolumn{2}{|l|}{ UNIDADE 1} \\
\hline $\begin{array}{l}\text { Aproveite a temática do sistema de numeração egípcio e do sistema } \\
\text { de numeração romano para promover uma aula interdisciplinar com } \\
\text { História e com Geografia, falando sobre os séculos e mostrando aos } \\
\text { alunos a localização das civilizações na época. (DANTE, 2017, p. } \\
\text { 15) }\end{array}$ & KPM \\
\hline
\end{tabular}

Universidade Federal de Mato Grosso, Cuiabá, Mato Grosso, Brasil. Revista REAMEC - Rede Amazônica de Educação em Ciências e Matemática, v. 10, n. 1, e22009, janeiro-abril, 2022. 
Aproveite a oportunidade para levar os alunos a refletir sobre a importância do consumo consciente; se julgar conveniente, pergunte a eles se já vivenciaram a situação de receber troco a mais ou a menos e leve-os a pensar nas atitudes mais adequadas em cada uma dessas situações. (DANTE, 2017, p. 21)

Aproveite o assunto para relacionar com os alunos as palavras par e ímpar com completo e incompleto, suficiente e insuficiente, feliz e infeliz, etc. Esclareça que os prefixos in- e im- significam 'não', ou seja, indicam negação. Assim, ímpar significa 'não par'. (DANTE, 2017, p. 23)

Ao trabalhar este tópico com os alunos, observe se eles estão utilizando corretamente os sinais de é maior do que (.), é menor do que (,) e é igual a (5). Explore diferentes estratégias de comparação, como usando a reta numerada, observando o quadro de números ou comparando os algarismos das ordens. (DANTE, 2017, p. 25)

Antes de iniciar as explorações deste tópico, leve os alunos a um espaço amplo, como a quadra ou o pátio da escola, e realize algumas explorações concretas. Por exemplo, solicite que se organizem do mais baixo para o mais alto (e, depois, do mais alto para o mais baixo), do mais novo para o mais velho (e, depois, do mais velho para o mais novo) ou outras explorações que permitam reflexões sobre ordem crescente e ordem decrescente, ainda sem o uso dessas nomenclaturas. (DANTE, 2017, p. 26)

\section{UNIDADE 2}

A Geometria dos anos iniciais do Ensino Fundamental deve ser a experimental ou manipulativa, na qual os alunos manipulam objetos ou embalagens, descobrem os elementos e as características ou propriedades deles e, também, as diferenças e as semelhanças entre eles. (DANTE, 2017, p. 34)

Nesta coleção, optamos por trabalhar apenas os sólidos geométricos (prismas, pirâmides, cones e cilindros) retos, deixando os oblíquos para os anos posteriores. Essa escolha é comum no ensino de Matemática para essa faixa etária. (DANTE, 2017, p. 37)

Esta atividade explora a percepção e a identificação de um sólido geométrico com características diferentes (o "sólido intrometido") em um conjunto de outros sólidos geométricos que têm as mesmas características. Observe que os sólidos geométricos estão representados em diferentes posições, o que pode dificultar o reconhecimento deles. Aproveite a oportunidade para explicar aos alunos que a posição em que o sólido geométrico é representado não interfere na forma nem nas propriedades dele. (DANTE, 2017, p. 43) 


\begin{tabular}{|l|l|}
\hline $\begin{array}{l}\text { É interessante que cada aluno trabalhe, por exemplo, com uma caixa } \\
\text { de creme dental (que lembra o paralelepípedo), para que possa }\end{array}$ & \\
manipulá-la e perceber que é uma figura com 3 dimensões: & KSM \\
comprimento, largura e altura. Ao desmontá-la, o aluno vai perceber & \\
que as partes que a formam são regiões planas com apenas 2 & \\
dimensões: comprimento e largura. (DANTE, 2017, p. 44) & \\
\hline $\begin{array}{l}\text { As respostas deles certamente trazem vários indícios do nosso } \\
\text { trabalho e nos fornecem parâmetros sobre a necessidade ou não de } \\
\text { replanejamento das aulas e das estratégias de ensino. (DANTE, } \\
\text { 2017, p. 60) }\end{array}$ & KFLM \\
\hline
\end{tabular}

Quadro 01- Primeira e Segunda unidades.

Fonte: Produzido pelo autor (2021)

No primeiro quadro encontramos todos os subdomínios do modelo MTSK, mas de maneira inversa na unidade 01 do manual encontramos predominantemente o domínio conhecimento pedagógico do conteúdo-PCK, e na unidade 02 encontramos o conhecimento matemático-MK em maior número, os subdomínios pertencentes ao PCK refletem a base de ensino eficaz, permite ao professor refletir sua prática em qualquer nível de ensino que ele esteja atuando, o MK por sua vez permite ao professor um conhecimento as características inerentes a matemática e suas regras esse equilíbrio faz com que o professor ao utiliza o manual consiga mobilizar o maior número de subdomínios e aperfeiçoar sua prática com a ajuda do modelo.

\section{Unidades 3 e 4: Adição e subtração grandezas e medidas}

Assim como nas outras unidades do manual a coleção se preocupa em iniciar cada capítulo de conteúdo com noções iniciais do tema, colocando as ideias introdutórias, por meio de perguntas, para que os alunos iniciem já uma reflexão desde a primeira apresentação do assunto, obtendo o retorno imediato do que já está internalizado na criança, para depois aumentar a "dificuldade" do tema gradativamente, ou seja, a especificidade das operações propostas. Esta terceira unidade aborda as duas operações básicas de adição e subtração, mas expandindo para os cálculos com resultados até 999, trabalhando com a resolução de problemas nos exercícios de fixação ao final.

Objetivos desta Unidade • Retomar as ideias da adição e da subtração. • Compreender os algoritmos da adição e da subtração sem reagrupamento. • Compreender os algoritmos da adição e da subtração com reagrupamento. • Resolver problemas envolvendo adição e subtração. (DANTE, 2017, p. 64)

Na quarta unidade os exemplos de medida de tempo inicialmente com várias ilustrações de objetos utilizados para medir, os minutos as horas, os meses, mostrando primeiramente a história por trás destas medidas, incentivando a conversa e a pesquisa sobre o tema, abordando 
como era medido o tempo por outras civilizações, por intermédio da própria natureza, como a posição do sol e as mudanças da lua. Com o passar do tempo foram criados diversos instrumentos para constatar as medidas com precisão. Com isso notamos claramente que os objetivos propostos a seguir, podem ser alcançados. "Objetivos desta Unidade • Reconhecer horas, minutos e segundos e a relação entre eles. • Reconhecer dias, semanas, meses e anos e a relação entre eles. • Trabalhar com o calendário. • Reconhecer as notas (cédulas) e as moedas do dinheiro brasileiro e saber contá-las". (DANTE, 2017, p. 94)

Trazendo para o dia-a-dia com exemplificações simples, de onde, como e quando nos deparamos com essas medidas, encontramos um inúmeras possíveis respostas, por se tratar de diferentes alunos, com percepções de mundo distintas, alimentando o vasto campo de ideias a serem exploradas em sala de aula. Ao final desta unidade, trabalha-se educação financeira com as crianças. Ensinando o sistema monetário, sem dúvida o dinheiro é o mais comum entre os exemplos, está de fato na vida das crianças desde o seu nascimento, nas conversas dos familiares, nos comércios locais, mostrando para nós que o manual se preocupa em trazer os conteúdos com mais significado e sentido para os alunos.

O quadro a seguir foi organizado destacando predominantemente os subdomínios do MK na terceira e quarta unidades de conteúdo, evidenciando que a matemática é estabelecida principalmente pelas conexões encontradas inter-conceitual e intra-conceitual, por mais que estejamos trabalhando com outras áreas ou linguagens, “em termos da própria matemática (tópicos, conexões, maneiras de proceder), de modo que a inclusão de itens seja independente do nível em que professor está trabalhando" (CARRILLO, 2018, p. 6).

\begin{tabular}{|l|c|}
\hline \multicolumn{1}{|c|}{ TRECHO } & $\begin{array}{c}\text { SUBDOMINIO } \\
\text { MTSK }\end{array}$ \\
\hline \multicolumn{2}{|c|}{ UNIDADE 3 } \\
\hline $\begin{array}{l}\text { Conduza as atividades oralmente, permitindo que eles conversem } \\
\text { entre si. Explore e valorize os conhecimentos prévios de cada um. } \\
\text { (DANTE, 2017, p. 66) }\end{array}$ & KPM \\
\hline $\begin{array}{l}\text { Cálculo mental, arredondamentos, estimativas e resultados } \\
\text { aproximados são fundamentais em situações do dia a dia. Incentive } \\
\text { os alunos a usar esses procedimentos ao longo do ano letivo, não só } \\
\text { em atividades como estas, que envolvem a operação de adição. } \\
\text { (DANTE, 2017, p. 68) }\end{array}$ & KMT \\
\hline $\begin{array}{l}\text { A adição sem reagrupamento é apresentada em uma situação- } \\
\text { problema nesta atividade. Para resolvê-la, é conveniente levar em } \\
\text { consideração as seguintes etapas: compreender o problema, planejar }\end{array}$ & KOT \\
\hline
\end{tabular}


a solução, executar os planos, verificar os resultados e, por fim, responder ao problema. (DANTE, 2017, p. 70)

Explore também a oralidade, solicitando aos alunos que expliquem o raciocínio que utilizaram para resolver cada atividade; assim, eles socializam suas estratégias e conhecem as outras estratégias que os colegas utilizaram. (DANTE, 2017, p. 78)

O algoritmo da subtração com reagrupamento é apresentado na situação-problema desta atividade. Peça aos alunos que representem a situação e as trocas com o dinheiro do Meu bloquinho, para depois registrar no algoritmo usual tudo o que for feito. (DANTE, 2017, p. 80)

\section{UNIDADE 4}

As grandezas e suas medidas são enfatizadas em toda esta coleção, por sua aplicabilidade no dia a dia, sendo trabalhadas ao longo do livro, e não isoladamente no final do volume. Nesta Unidade estudamos a medida de tempo (em horas, minutos, segundos, dias, semanas, meses e anos) e o dinheiro brasileiro. (DANTE, 2017, p. 94)

Esta atividade pode ser ampliada nas aulas de História e Geografia. Outra ampliação possível é explorar com os alunos um relógio d'água e o funcionamento dele. (DANTE, 2017, p. 97)

Nas atividades deste tópico exploramos as noções de hora e meia hora, estendendo para as noções de meio-dia e meia-noite, retomando o que foi trabalhado nos volumes anteriores desta coleção e aprofundando um pouco mais. (DANTE, 2017, p. 98)

As atividades deste tópico relacionam 3 unidades de medida de tempo: hora, minuto e segundo. Em sala de aula, proponha atividades simples para que os alunos percebam o "tempo" de 1 segundo. Por exemplo, peça que andem 3 passos e percebam o tempo que demora. (DANTE, 2017, p. 104)

Nas atividades deste tópico os alunos trabalham com as unidades de medida de tempo dia e semana, para retomar e aprofundar o que foi estudado nos volumes anteriores desta coleção. O trabalho com o calendário é muito importante na compreensão da grandeza tempo e dessas unidades de medida. (DANTE, 2017, p. 107)

\section{Quadro 02- Terceira e Quarta unidades.}

Fonte: Produzido pelo autor (2021)

Neste segundo quadro encontramos cinco subdomínios diferentes, tanto na terceira quanto a quarta unidades aparecem o conhecimento pedagógico do conteúdo-PCK, em maior número de vezes, notamos que para o professor mobilizar tal subdomínio, é de extrema importância a sua prática, pois “o foco específico do PCK está relacionado à própria 
matemática. Mais do que ser sobre a interseção entre conhecimentos matemáticos e pedagógicos gerais" (CARRILLO, 2018, p.11). Embora deva ser complementado pela metodologia presente no domínio do conhecimento matemático- MK.

\section{Unidades 5 e 6: Multiplicação e Divisão.}

Essa unidade compartilha as outras usa operações básicas, podemos trazer a ideia de verso e inverso compactando os conteúdos, por meio de exercícios de fixação, brincadeiras e gincanas para o aprendizado dentre outros desafios essas unidades são complexa e para alguns alunos é muito difícil a compreensão. Nessa etapa podemos associar essas operações com as outras que iniciamos no ano letivo, formando uma rede de informações sucessivas, que fixam o conteúdo de maneira efetiva, como a ideia de somar sucessivamente um número para explicar a multiplicação ou até mesmo a ideia de reparti-lo em determinadas quantidades.

Objetivos desta Unidade 5 • Reconhecer as ideias associadas à multiplicação. • Trabalhar as tabuadas do 2 ao 10. • Reconhecer as noções de dobro e triplo. • Apresentar estratégias para efetuar a multiplicação. • Resolver problemas envolvendo multiplicação. (DANTE, 2017, p.118)

A apresentação das tabuadas ocorre de maneira interessante neste didático, pois se da em dois momentos, na retomada das tabuadas do 2 ao 5, já ensinada no segundo ano, de acordo com a BNCC e outros componentes curriculares, que a coleção adotou como base, mas, agora com a apresentação de mais quatro tabuadas, o que permite aos alunos perceber as regularidades presentes nelas e após esse discernimento a memorização e internalização do conceito de multiplicação.

Objetivos desta Unidade 6 • Compreender as ideias da divisão. • Explorar as ideias de metade e de terça parte. • Reconhecer que a multiplicação e a divisão são operações inversas. • Resolver problemas envolvendo a divisão. (DANTE, 2017, p. 146)

Com a exemplificação através de exemplos diversos, podemos associar juntamente com as crianças, as operações presentes nas equações, e descobrir as inversões que são feitas no cálculo de cada uma delas. A prática faz com que diferentes estratégias sejam aderidas e utilizadas no cálculo dessas operações. Fechando as quatro operações básicas com a divisão, compartilhando situações que já vivenciaram anteriormente, mesmo sem conhecer o modo como funcionava a operação.

No quadro abaixo destacamos que na quinta unidade do manual, o MK se sobressai principalmente o subdomínio KPM, onde "o foco está no funcionamento da matemática, em vez do processo de ensiná-lo" (CARRILLO, 2018, p. 9). Na sexta unidade porém, o KMT, é 
visto o maior número de vezes, "esse subdomínio diz respeito ao conhecimento intrinsecamente ligado ao conteúdo, com exclusão de aspectos do conhecimento pedagógico geral" (CARRILLO, 2018, p. 12).

\begin{tabular}{|c|c|}
\hline TRECHO & $\begin{array}{l}\text { SUBDOMINIO } \\
\text { MTSK }\end{array}$ \\
\hline \multicolumn{2}{|l|}{ UNIDADE 5} \\
\hline $\begin{array}{l}\text { Nesta unidade, trabalhamos as ideias associadas à multiplicação: } \\
\text { adição de quantidades iguais, disposição retangular e possibilidades. } \\
\text { Em seguida, apresentamos situações que envolvem essas ideias. } \\
\text { Naturalmente, estará correto se os alunos indicarem com uma } \\
\text { adição uma situação típica de multiplicação. (DANTE, 2017, p. } \\
\text { 118) }\end{array}$ & KMT \\
\hline $\begin{array}{l}\text { Nas atividades deste tópico são trabalhadas as ideias associadas à } \\
\text { multiplicação: adição de quantidades iguais (atividades } 1 \text { e 2), } \\
\text { disposição retangular (atividade } 3 \text { e Explorar e descobrir) e } \\
\text { combinar possibilidades (atividades } 4 \text { e 5). (DANTE, 2017, p. 121) }\end{array}$ & KSM \\
\hline $\begin{array}{l}\text { As atividades deste tópico mostram diferentes estratégias para a } \\
\text { resolução de uma multiplicação (desenhando, usando papel } \\
\text { quadriculado e "andando" na reta numerada). Conhecer essas } \\
\text { estratégias é essencial para ampliar o repertório de resoluções. } \\
\text { (DANTE, 2017, p. 124) }\end{array}$ & KMT \\
\hline $\begin{array}{l}\text { Antes de iniciar as atividades, retome com os alunos as estratégias } \\
\text { que eles conheceram nesta Unidade para efetuar multiplicações e } \\
\text { anote-as na lousa ou em um cartaz para que, após a realização das } \\
\text { atividades deste tópico, possam ampliá-lo. (DANTE, 2017, p. 141) }\end{array}$ & KPM \\
\hline $\begin{array}{l}\text { Oriente os alunos a ler individualmente os enunciados das } \\
\text { atividades desta página e decidir qual estratégia vão utilizar. Depois, } \\
\text { eles compartilham a interpretação que fizeram do enunciado e a } \\
\text { estratégia que utilizaram para resolvê-la. (DANTE, 2017, p. 142) }\end{array}$ & KMLS \\
\hline \multicolumn{2}{|l|}{ UNIDADE 6} \\
\hline $\begin{array}{l}\text { Exploramos nesta Unidade as ideias da divisão: a ideia de repartir } \\
\text { igualmente e a de medida traduzida pela pergunta: "Quantos } \\
\text { cabem?". Trabalhamos a ideia de metade e de terça parte, } \\
\text { relacionamos as operações de multiplicação e de divisão. (DANTE, } \\
\text { 2017, p. 146) }\end{array}$ & KOT \\
\hline $\begin{array}{l}\text { Resgate com os alunos as situações cotidianas relacionadas ao ato } \\
\text { de dividir e as estratégias que eles utilizam em cada uma. }\end{array}$ & KMLS \\
\hline
\end{tabular}




\begin{tabular}{|l|l|}
\hline $\begin{array}{l}\text { Desenvolva com eles atividades com o uso de material concreto. } \\
\text { (DANTE, 2017, p. 149) }\end{array}$ & \\
\hline $\begin{array}{l}\text { Aproveite a temática das conchinhas desta atividade para conversar } \\
\text { com eles sobre o tema contemporâneo educação ambiental, citando, } \\
\text { por exemplo, os cuidados que devemos ter em não retirar animais } \\
\text { do habitat natural. (DANTE, 2017, p. 152) }\end{array}$ & \\
\hline $\begin{array}{l}\text { Assim como fizemos com a adição e a subtração, nas atividades } \\
\text { deste tópico relacionamos a multiplicação e a divisão como } \\
\text { operações inversas. Utilize diferentes estratégias para a } \\
\text { compreensão dos alunos. (DANTE, 2017, p. 156) }\end{array}$ & KS \\
\hline $\begin{array}{l}\text { As atividades e os problemas deste tópico trabalham as } 4 \text { operações } \\
\text { estudadas: adição, subtração, multiplicação e divisão. Ao trabalhar } \\
\text { com a possibilidade de a atividade envolver qualquer uma das } \\
\text { operações, os alunos são estimulados a "pensar mais" em como } \\
\text { resolver, pois não tem como pré-requisito a informação de qual } \\
\text { operação devem utilizar. (DANTE, 2017, p. 160) }\end{array}$ & \\
\hline \multicolumn{2}{|c|}{ Quadro 03 - Quinta e Sexta unidades. } \\
\hline
\end{tabular}

Esse quadro é o que mais se diferenciou de uma unidade para outra, na unidade cinco os subdomínios do MK aparecem duas vezes e o PCK apenas três. Já na sexta unidade o MK aparece quatro vezes e o PCK somente uma vez, o KOT é o que mais se destaca, isso é importante pois é o subdomínio que nos "descreve o que e de que maneira o professor de matemática conhece os tópicos que ele ensina; implica conhecimento profundo do conteúdo matemático" (CARRILLO, 2018, p.07)

\section{Unidades 7 e 8: grandezas e medidas: comprimento, massa e capacidade e Números maiores que 1000.}

Essas unidades são de suma importância, afinal na unidade sete podemos mobilizar todo o capital acumulado das unidades anteriores e trabalhar interdisciplinarmente, utilizando-se de unidade padrão para iniciar. "Objetivos desta Unidade - Explorar as grandezas comprimento, massa e capacidade, apresentando algumas de suas unidades de medida. • Resolver problemas envolvendo essas grandezas.” (DANTE, 2017, p. (168)

Se providenciarmos os utensílios utilizados na medição de forma palpável, podemos estimular a interpretação, de cada uma, e de maneira concreta observar o contato deles com os objetos e auxiliar na manipulação correta dos mesmos. Os objetivos encontrados para a oitava e última unidade, mesmo que pareçam mais simples, podem gerar situações-problema complexas para a resolução. São eles: 
Objetivos desta Unidade $\bullet$ Ler, escrever e ordenar números até 10 000. Compor e decompor números até 10000 . O Operar com números até 10 000. • Resolver situações-problema em que apareçam números até 10.000. (DANTE, 2017, p. 196)

Nesta última unidade o autor inicia para o próximo ano letivo os números maiores que mil, como foi trabalhado na primeira unidade do livro, esta unidade é bem pequena, com objetivos mais curtos, mesmo que seja de finalização podemos entender como sendo introdutória pois temos descrito os números até dez mil, pela primeira vez no currículo, então pode ser encarada como a preparação do próximo ano letivo, assim a responsabilidade aumenta ao tratar desse assunto.

Chegamos ao final do manual e mais uma vez a influência dos domínios se invertem nessas duas unidades finais, a sétima unidade o MK aparece três vezes, o KSM que "reconhece as conexões temporais que sublinham o papel generativo dos itens matemáticos na construção de outros itens" (CARRILLO, 2018, p. 8) e o KPM "pode ser geral ou específico para um tópico" (CARRILLO, 2018, p.10). Na oitava unidade encontramos os três subdomínios do PCK, nos mostrando a importância da prática do professor em sala de aula, para que o ensino seja eficaz, além de permitir ao professor ser crítico e reflexivo, para finalizar essa unidade de conteúdo, com os conceitos bem fundamentados para o início do próximo ano, como demonstrado nos objetivos da coleção ÁPIS, com seus tópicos organizados de forma "espiral".

\begin{tabular}{|c|c|}
\hline TRECHO & $\begin{array}{c}\text { SUBDOMINIO } \\
\text { MTSK }\end{array}$ \\
\hline \multicolumn{2}{|l|}{ UNIDADE 7} \\
\hline $\begin{array}{l}\text { As medidas funcionam como ponte de integração entre as grandezas } \\
\text { geométricas (comprimento, superfície e volume) e os números e } \\
\text { também entre estes e outras grandezas, como massa, tempo, } \\
\text { temperatura, valor monetário, etc. Além disso, desenvolvem o } \\
\text { sentido de número e de tamanho por meio de estimativas. (DANTE, } \\
2017 \text {, p. 168) }\end{array}$ & KMT \\
\hline $\begin{array}{l}\text { O trabalho com as unidades não padronizadas de medida de } \\
\text { comprimento (palmo, pé e passo), nas atividades deste tópico, } \\
\text { mostra a necessidade de introduzir as unidades padronizadas de } \\
\text { medida de comprimento, como o centímetro e o metro, que virão } \\
\text { em seguida. (DANTE, 2017, p. 171) }\end{array}$ & KSM \\
\hline $\begin{array}{l}\text { Ensine os alunos a utilizar corretamente a régua para medir } \\
\text { comprimentos. Um erro frequente é começar a medição pelo } 1 \text {, } \\
\text { quando o correto é iniciar pelo } 0 \text {. Existem algumas réguas que têm }\end{array}$ & KPM \\
\hline
\end{tabular}


um pequeno espaço antes de iniciar os números. Chame a atenção dos alunos para esses detalhes. (DANTE, 2017, p. 172)

Antes de começar este tópico, retome com os alunos o número 1 000, estudado na Unidade 1 deste livro. Em seguida, pergunte a eles em que situações do dia a dia eles já ouviram a referência ao quilômetro e relacione-o com a unidade de medida metro, já estudada nesta Unidade. (DANTE, 2017, p. 178)

Nas atividades deste tópico são abordados estimativas e cálculo de medidas de capacidade utilizando a unidade padronizada de medida litro. Também é apresentada a unidade de medida mililitro e a relação dela com o litro. (DANTE, 2017, p. 185)

\section{UNIDADE 8}

As ideias de unidade, dezena, centena e unidade de milhar são trabalhadas também com o material dourado ou material de base dez. A composição, a decomposição e a leitura de um número também são feitas. (DANTE, 2017, p. 196)

As atividades deste tópico visam propiciar aos alunos um breve contato com os números maiores do que 1000 , pois eles fazem parte do dia a dia deles. Retome com os alunos os números até 999 estudados na Unidade 1 deste livro e o número 1000 , que foi citado na página 31. (DANTE, 2017, p. 199)

Esta atividade apresenta uma situação de adição com valores monetários, que pode ser interpretada pela composição do número 1000 com um número até 999. Crie outras situações semelhantes a essa, para que eles calculem o saldo final. (DANTE, 2017, p. 201) Esta atividade apresenta os milhares inteiros ou milhares exatos, por meio de multiplicações do número 1 000, e a leitura deles. Peça aos alunos que leiam em voz alta os números obtidos. Aproveite esta atividade para retomar com eles a regularidade ao multiplicar um número por 10, 100 ou 1000 e observe se eles utilizam essa regularidade para obter o número de cada item. (DANTE, 2017, p. 203)

Para ampliar esta atividade, peça aos alunos que retomem também a tabela que elaboraram na abertura desta Unidade, com o ano de nascimento deles e dos familiares, e escrevam a leitura do número de cada ano. (DANTE, 2017, p. 207)

\section{Quadro 04 - Sétima e Oitava unidades.}

Fonte: Produzido pelo autor (2021)

Este quadro foi o que as unidades temáticas se igualaram em relação aos domínios, em ambas as unidades analisadas e trechos retirados, encontramos predominantemente o conhecimento matemático-MK, em especial o KSM foi o que mais se destacou, estes 
subdomínios "reconhece as conexões temporais sublinhando o papel generativo de itens matemáticos na construção de outros itens, razão pela qual eles transcendem a sequência currículo simples." (CARRILLO, 2018, p.08) ou seja, as últimas unidades do manual além de se preocupar com a sequência simples do currículo, ainda estimula a criatividade para o ano seguinte, fazendo com que matemática seja reconhecida e representada de diversas formas.

\section{CONSIDERAÇÕES FINAIS}

Os subdomínios aparecem em geral, de maneira equilibrada, nos trechos analisados são os pertencentes ao MK aparecem 23 vezes e os que são oriundos do PCK aparecem 17 vezes; mas podemos notar que em cada unidade varia a sua predominância, em cada unidade um domínio se sobressai, de acordo com o conhecimento especializado que cada professor deve mobilizar para realizar as atividades propostas.

Nas unidades 02, 03, 04, 06,07 e 08 prevalecem os subdomínios pertencentes ao MK, o que nos leva a perceber a importância do professor, conhecer a matemática e os processos de formação, construção e fundamentação que é necessário para que os alunos a compreendam. Nas unidades 01 e 05 sobressaem os subdomínios do PCK, que complementa o conhecimento dos currículos e dos conteúdos, trazendo um foco da pedagogia para ensinar, atribuída ao professor que ensina matemática em sala de aula, lembrando que a abordagem, a pesquisa e a reflexão, são exclusivas, ou seja, se diferencia do professor que ensina engenharia por exemplo.

Portanto, é de fundamental importância que as pesquisas em educação matemática avancem, para que a iniciativa docente seja de maneira intencional, efetivamente positiva, fazendo com que os alunos entendam de fato a linguagem matemática e encarem a disciplina com mais leveza, percebendo que no dia a dia, podemos fazem conexões entre a teoria e a sua aplicabilidade, utilizar exemplos cotidianos para garantir o entendimento necessário no ensino. Sabemos que as metodologias e os recursos usados em sala de aula são escolhidos pelos professores e seguir as orientações ficam a critério de cada um, mas entender a relevância de localizar o conhecimento especializado faz com o aprimoramento de suas ações sejam mais rápidos e conscientes.

\section{REFERÊNCIAS}

CARRILLO J. Y. et al. The mathematics teacher's specialised knowledge (MTSK) model. Research in Mathematics Education. v.20 ed 3, 2018. 
DANTE. L. R. Alfabetização Matemática de $3^{\circ}$ ano - Manual didático do professor. 3 ed.

São Paulo: Editora Ática, 2017.

LÜDKE, M. Pesquisa em Educação: Abordagens Qualitativas. São Paulo: EPU, 1986.

MORIEL JUNIOR, J. G. Conhecimento especializado para ensinar divisão de frações. Tese (Doutorado em Educação em Ciências e Matemática), Rede Amazônica de Educação em Ciências e Matemática (REAMEC), Universidade Federal de Mato Grosso - UFMT, 2014.

MORIEL JUNIOR, J. G.; CARRILLO, J. Explorando indícios de conhecimento especializado para ensinar matemática com o modelo MTSK. In: Seminario de Investigación en

Educación Matemática XVIII, Salamanca: SEIEM, 2014. p. 465-474. Disponível em: http://funes.uniandes.edu.co/6087/1/Moriel2014ExplorandoSEIEM.pdf. Acesso em: abr. 2021.

\section{APÊNDICE 1}

\section{AGRADECIMENTOS}

Agradecemos a Bolsa PIBIC da Universidade Federal da Grande Dourados

\section{FINANCIAMENTO}

Agradecemos a Bolsa PIBIC da Universidade Federal da Grande Dourados

\section{CONTRIBUIÇÕES DE AUTORIA}

A participação da escrita e elaboração deste estudo foi realizada igualmente pelas autoras Camila Fernanda Pereira da Luz e Edvonete Souza de Alencar

\section{CONFLITOS DE INTERESSE}

Não possuímos conflitos de interesse.

\section{DISPONIBILIDADE DE DADOS DE PESQUISA}

Declaramos que foram disponibilizados os dados da pesquisa na composição do próprio artigo.

\section{CONSENTIMENTO DE USO DE IMAGEM}

As imagens utilizadas estão referenciadas e possuímos autorização de uso.

\section{APROVAÇÃO DE COMITÊ DE ÉTICA EM PESQUISA}

A investigação por ser documental e bibliográfica não necessita de comitê de ética por que não atua com pessoas.

\section{COMO CITAR - ABNT}

LUZ, C. F. P.; ALENCAR, E. S. Os conhecimentos do professor para ensinar matemática no manual didático brasileiro do terceiro ano do ensino fundamental. REAMEC - Rede Amazônica de Educação em Ciências e Matemática. Cuiabá, v. 10, n. 1, e22009, janeiro-abril, 2022. http://dx.doi.org/10.26571/REAMEC.

\section{COMO CITAR - APA}

LUZ, C. F. P.; ALENCAR, E. S. (2022). Os conhecimentos do professor para ensinar matemática no manual didático brasileiro do terceiro ano do ensino fundamental. REAMEC - Rede Amazônica de Educação em Ciências e Matemática, 10(1), e22009. http://dx.doi.org/10.26571/REAMEC.

\section{LICENÇA DE USO}

Licenciado sob a Licença Creative Commons Attribution-NonCommercial 4.0 International (CC BY-NC 4.0). Esta licença permite compartilhar, copiar, redistribuir o manuscrito em qualquer meio ou formato. Além disso, 
permite adaptar, remixar, transformar e construir sobre o material, desde que seja atribuído o devido crédito de autoria e publicação inicial neste periódico.

\section{DIREITOS AUTORAIS}

Os direitos autorais são mantidos pelos autores, os quais concedem à Revista REAMEC - Rede Amazônica de Educação em Ciências e Matemática - os direitos exclusivos de primeira publicação. Os autores não serão remunerados pela publicação de trabalhos neste periódico. Os autores têm autorização para assumir contratos adicionais separadamente, para distribuição não exclusiva da versão do trabalho publicada neste periódico (ex.: publicar em repositório institucional, em site pessoal, publicar uma tradução, ou como capítulo de livro), com reconhecimento de autoria e publicação inicial neste periódico. Os editores da Revista têm o direito de proceder a ajustes textuais e de adequação às normas da publicação.

\section{PUBLISHER}

Universidade Federal de Mato Grosso. Programa de Pós-graduação em Educação em Ciências e Matemática (PPGECEM) da Rede Amazônica de Educação em Ciências e Matemática (REAMEC). Publicação no Portal de Periódicos UFMT. As ideias expressadas neste artigo são de responsabilidade de seus autores, não representando, necessariamente, a opinião dos editores ou da referida universidade.

\section{EDITOR}

Rogerio dos Santos Carneiro

\section{HISTÓRICO}

Submetido: 17 de agosto de 2021.

Aprovado: 20 de dezembro de 2021.

Publicado: 01 de fevereiro de 2022. 